\section{Focusing elementary students with active classrooms: exploring teachers' perceptions of self-initiated practices}

\author{
Christine A. Foran ${ }^{a, *}$, Cynthia Mannion ${ }^{a}$, Gayle Rutherford ${ }^{a}$
}

\author{
Received: 14 June 2017 \\ Revised: 31 August 2017 \\ Accepted: 17 Sept. 2017 \\ ISSN: 1307-9298 \\ Copyright (C) IEJEE \\ www.iejee.com
}

DOI: 10.26822/iejee.2017131887

\begin{abstract}
The aim of our study was to explore the perceptions of elementary teachers who routinely prioritized physical activity in their classrooms. Researchers are reporting improved student academic test results following physical activity sessions, however, classroom teachers are challenged in balancing curricular and other expectations. Hence, teachers who voluntarily implement physical activity have views that are unique and important for promoting the practice to others. We interviewed seven teachers from grades 1-6, using the qualitative constructivist approach to grounded theory qualitative research. Teachers valued physical activity because it enhanced their students' focus on classroom activities. Common attributes amongst the teachers were active lifestyles, previous employment experiences using physical activity, and a pedagogical approach prioritizing physical activity throughout the day. Additionally, the teachers perceived that belonging to schools with a culture of movement was important. Teachers view physical activity as a teaching asset when they perceive a positive impact on their students' ability to focus. Specific teacher attributes and a school environment that embraces physical activity may predispose teachers to these views, and represent areas that should be further explored. Pre-service courses could be one way to provide teachers with experience and a repertoire of easy physical activities.
\end{abstract}

Keywords: Physical activity, focus, teachers, perceptions, culture.

\section{Introduction}

Physical activity is a foundational component of maintaining health and wellbeing across the lifespan (World Health Organization (WHO), 2016). Regular physical activity is also a strategy to overcome the increasing rates of childhood obesity and associated morbidity (ParticipACTION, 2016). Debate surrounds the frequency of physical activity in schools. Advocates feel physical activity should be prioritized as integral to student learning due to the effects on the growth and development of school children (Khan \& Hillman, 2014), and as a way of combatting increasingly sedentary lifestyles (ParticipACTION, 2016). Those opposing increasing physical activity in schools, view the reduction of time spent on academics as negative. Schools represent a convenient environment where children can be targeted for physical activity and exposure to physically active role models. Although teachers are challenged to meet all expectations, some teachers regularly prioritize physical activity in their classrooms. These teachers' perceptions should be understood and explored to highlight the benefits they perceive for their students.

\section{Childhood Physical Inactivity}

Physical inactivity is a leading risk factor of global mortality (WHO, 2016). Only $19.7 \%$ of $13-15$ year olds worldwide meet the recommendation of 60 minutes daily of physical activity (Hallal et al., 2012). In Canada, 76\% of 5-17 year olds are sedentary for more than two hours daily through on screen time, and only $25 \%$ of children typically walk to school (ParticipACTION, 2016). There is a $33 \%$ incidence of overweight 5-17 year olds (Roberts, Shields, de Groh, Aziz, \& Gilbert, 2012), and they are at increased risk of remaining overweight or obese for life (Singh, Mulder, \& Twisk, 2008). Physical inactivity is directly linked to "coronary heart disease, type 2 diabetes, and breast and colon cancers" (Lee et al., 2012, p. 1). Hence, increasing the physical activity levels of children has the potential to affect their health long term.

Many people assume that in school, students receive adequate opportunities for physical activity during recess and physical education classes, but students can choose non-active options at recess, and physical education is often not provided daily (Centers for Disease Control and Prevention, 2007; Maeda \& Murata, 2004). To help

\footnotetext{
* Corresponding author: Christine A. Foran, University of Calgary, Faculty of Nursing, 2500 University Drive NW, Calgary, Alberta, CANADA T2N 1N4. Email: caforan@ucalgary.ca

a University of Calgary, Faculty of Nursing, Calgary, Alberta, CANADA. E-mail addresses: (C. Mannion) cmannion@ucalgary.ca; (G. Rutherford) geruther@ucalgary.ca
} 
children combat the effects of inactivity, students can be provided opportunities for physical activity in their classrooms during lessons or as transitions between subjects. Increasing students' physical activity during each school day is an upstream approach to reducing inactivity and has important implications for student learning.

\section{Physical Activity and School Performance}

Physical activity should be promoted within schools because of the impact on students' growth and development and "improved learning and mental performance" (Cotman \& Berchtold, 2002, p. 295). Researchers documented that physical activity has positive effects on students academic test scores (Donnelly \& Lambourne, 2011; Erwin, Fedewa, \& Ahn, 2013; Hill et al., 2010; Hill, Williams, Aucott, Thomson, \& Mon-Williams, 2011; Kibbe et al., 2011; Maeda \& Randall, 2003; Reed et al., 2010) and on task behaviors (Bartholomew \& Jowers, 2011; Carlson et al., 2015; Kibbe et al., 2011; Mahar et al., 2006; Miramontez \& Schwartz, 2016). In a meta-analysis of 44 studies, Sibley and Etnier (2003) found a significantly positive relationship (effect size $0.32, p<.05)$ between physical activity and cognitive abilities of children. They noted that the strongest relationship between physical activity and cognition occurred for children aged 4-13 years (Sibley \& Etnier, 2003). They offered the possible explanation that "young children learn best when they are moving" (Sibley \& Etnier, 2003, p. 252). Hillman, Erickson, and Kramer (2008) postulated that Sibley and Etniers' findings suggest that, "early intervention might be important for the improvement and/or maintenance of cognitive health and function throughout the adult lifespan" (p. 59). Hence, schools should act on the growing evidence that physical activity boosts students' early academic achievements.

Elementary teachers spend 6-8 hours daily with their students, and thus represent students' best opportunity for physical activity and for improvements in learning, health, and an introduction to lifelong habits. Several studies have targeted teachers' perceptions of their use of physical activity (Cothran, Hodges-Kulinna, \& Garn, 2010; Dinkel, Schaffer, Snyder, \& Lee, 2017; Gately, Curtis, \& Hardaker, 2013; Gibson et al, 2008; Howie, NewmanNorlund, \& Pate, 2014; Maeda \& Murata, 2004; Martin \& Murtagh, 2015; McMullen, Kulinna \& Cothran, 2014; Stylianou, Hodges-Kulinna, \& Naiman, 2016). However, few studies have been done on teachers who self-initiate regular physical activity in their classrooms-independent of a specific program or study that is aimed to increase student activity levels. Teachers who have instigated and sustained their use of classroom physical activity in the classroom have valuable perceptions of their experiences. In addition, teachers' instigating physical activity independent of an intervention study or program implementation, represent a unique addition to the existing literature. Thus, their perceptions should be explored to promote similar practices.

\section{Methods}

Research Design
The research question guiding this study was, "What are teachers' perceptions of the factors and processes that instigate and sustain their use of classroom physical activity?" We chose a qualitative approach to gain a rich understanding of teachers' experiences and perceptions of using physical activity in their classrooms. Grounded theory has no preconceived hypothesis and requires constant comparative analysis of the data. It uses "systematic, yet flexible guidelines for collecting and analyzing qualitative data" (Charmaz, 2014, p.1). We chose the constructivist approach to grounded theory methods to move beyond description and to understand the processes and actions behind the phenomenon of teachers instigating and sustaining physical activity (Charmaz, 2014). The constructivist methodology also allowed the principal investigator to acknowledge personal experience as a public health nurse practicing in schools (Charmaz, 2014). Interviews functioned as reflexive exchanges and co-constructions of understanding, whereby participants also gained increased understanding.

\section{Participants}

There were seven participants from seven different schools located across all quadrants of a western Canadian city. The city population was greater than $1,000,000$ people, and was comprised of $30 \%$ of visible minority groups (Statistics Canada, 2011). Four teachers taught in grades 1-3, two teachers taught grades $4-6$, and one taught students in grades 1-6. Six teachers were female, one was male. Teachers had 4-24 years of teaching experience, two had graduate degrees, and their ages ranged from 23-50 years. All teachers were Caucasian but many commented on their awareness of diversity in their classrooms and the impact of school culture on physical activity levels of their students.

The study was approved by the Conjoint Health Research Ethics Board and one of the city's school jurisdictions for research, which granted access to the participants. The inclusion criteria for teachers included: 1 ) teaching grades 1-6 in the city school system, 2) representation from all quadrants of the city, 3) both primary division of grades 1 3 and secondary division of grades $4-6$, and 4) the self identification of regular use of classroom physical activity. Classroom physical activity was defined as any bodily movement requiring energy expenditure (WHO, 2014) for any amount time, in any setting (classroom, hallway, outside), as long as it was exclusive of physical education class or recess. Characteristics that excluded a teacher from acceptance into the study were those in an administrative role, a permanent physical education position, substitute teachers, or teacher's aides. To begin, we used purposive sampling to select participants. Once data collection was underway, we used theoretical sampling, based on the particular areas of relevance that required illuminating (Charmaz, 2014). To protect the anonymity of the participants, teachers will be referred to as P1-7 indicating the order that they were interviewed.

Teachers were contacted in one of four ways. First, the Comprehensive School Health Lead emailed recruitment letters to Health Champions-likely candidates for interviews. Second, the primary researcher (CF) attended 
two professional development sessions on physical activity. Third, colleagues aware of the study provided the contact information for participants willing to volunteer. Finally, recruitment emails were sent to principals and teachers with publicly available addresses from school websites.

We used theoretical sampling to select participants based on the particular areas of relevance that required illuminating (Charmaz, 2014). We determined that 8-12 teachers would be required to reach theoretical saturation, described as occurring when no new items are introduced (Charmaz, 2014). The number of participants was based on previous experience interviewing teachers, the number of teachers using classroom physical activity who might be available to interview, and the short time frame allowed by the school board to complete the interviews. A total of seven teachers were interviewed when theoretical saturation occurred.

\section{Procedures}

One investigator (CF) conducted all one on one interviews at the schools between January and April 2015. The semistructured interviews lasted one hour and were organized with open-ended questions to establish the topic and allow participants the opportunity to highlight important beliefs (Charmaz, 2014). Two experts reviewed the interview guide, which was revised following their feedback. Samples of the open-ended questions included: "Please tell me how you started using physical activity in your classroom?"; "Can you describe a typical day where you would incorporate physical activity?"; "Please describe any supports that are in place that you feel encourage your use of physical activity?"; and "What has the response been from other teachers in your school?" The investigator used probing questions to clarify participants' meanings and definitions. Interview questions evolved in subsequent interviews based on areas that the investigator felt needed clarification or exploration.

\section{Data Analysis}

The primary investigator transcribed all interviews verbatim. We followed the levels of analysis as outlined by Charmaz (2014): initial coding, focused coding, and constant comparison. Each transcript was analyzed before a new participant was interviewed, allowing for an understanding of the data and the emergence of new themes and directions to be explored in the next interview (Charmaz, 2014).

For the initial coding of the transcripts, we used line-byline coding to fragment the data- emphasizing the action and choosing participants' words to represent salient concepts (Charmaz, 2014). We started using focus coding after four interviews, scrutinizing the initial codes for potential analytic categories, comparing data with data, codes with data, codes with codes, and then analyzing for conceptual usefulness and salience (Charmaz, 2014). We used the constant comparative method through each level of analysis, creating interactions between the data, the codes, the concepts, drawing on relevant literature, and discerning the connections between categories (Charmaz, 2014). Transcripts were compared, reread, re- coded, and compared for similarities and differences. A second investigator reviewed four transcripts and coding to confirm objectivity and fit for emergent codes. Memos were written throughout all processes, during the interviews, analysis, and documentation. Memo writing was integral to the analysis of concepts, clarifying the research process, and making clear the multiple influences, assumptions, and standpoints (Charmaz, 2014).

\section{Findings}

Teachers spoke about three main themes when discussing their implementation of physical activity in their classrooms. First, their perception that students had improved focus on classroom work following a session of physical activity. Second, personal attributes such as: active lifestyles, previous experience using physical activity with children, and a pedagogical teaching approach prioritizing physical activity. Third, they perceived that belonging to a school with a culture of movement was important.

\section{Improved Student Focus}

Teachers reported that the impetus for inserting short sessions of physical activity was to focus students on their work. Teachers were attuned to a range of behaviors signaling that students were less focused, and indicating the necessity of a physical activity break. They described students as: "wired," "[having] unfocused energy," and causing "chaos," though unfocused students were also observed as "drifting off, [or] day dreaming." P7 was a grade (Gr.) two teacher who noted gender differences: "Girls...it's like passive disengagement, whereas boys tend to jump around a little more-it's more obvious [that the boys aren't paying attention]". P1 (Gr. 5/6) described the value of a movement break, "if you take 10 minutes [for physical activity], the quality of learning you'll get afterwards is usually better..."

When explaining why they used physical activity in the classroom, some teachers linked physical activity to their knowledge on self-regulation. While only some teachers were aware of the terminology, all teachers were aware that students had needs that required a response before learning could occur. Physical activity often met those needs. P7 (Gr. 2) recognized that often in her class, students asked to use the bathroom not because they needed to use the facilities, but because they needed to walk the hallway. P4 (Gr. 1/2) explained that it was her role to help students become aware of self-regulating behaviors. She explained,

One of our dreams for this school is to have a cycle bike down in one of the mud rooms so they can just go and burn it off [their physical energy that was fueling an inappropriate action]. The ultimate goal is to get them to self-regulate, but young kids don't often know in the beginning... So we're setting it up... You're feeling this way-these are your options. You do it pro-actively, and then eventually they can start choosing it on their own.

P6 (Gr. 5) related that she let students do their work lying on the carpet, at stand-up stations, or walking around. She stated, 
I'm not bothered by you listening to your body and doing what you have to do in my classroom. So if that means you're lying on this carpet... As long as I see work happening at the same time. They [the students] learn they're not really chained to their desks in here...

Hence, physical activity was not only used to focus students on their work, but also as an acceptable behavior in the classroom when students are learning to self-regulate.

\section{Teacher Attributes: Active Lifestyle}

All teachers reported a personal lifestyle choice that included physical activity, engaging in activities such as: hiking, biking, running, triathlon, swimming, walking, yoga, floor hockey, and basketball. They preferred an active lifestyle for: enjoyment, health maintenance, diagnoses requiring physical activity, and raising an active family. Teachers attributed value for themselves from physical activity, and some would participate with the students to derive the same benefits. P1 (Gr. 5/6) commented, "I just know for myself that when you're sitting there for a long period of time... You need to get up and move and stretch or you start to lose your focus..." P4 (Gr. 1/2) stated, "I wish the same benefit [the ability to move] was given to me as an adult in a meeting." P2 (Gr. 1-6) stated, "When my [fitness] class is over, and I'm driving home I just feel like a new person. Yeah!! It's huge! So I always try to remember that! (laughing) You'll feel better when it's finished!" P5 (Gr. 3) stated, "I know that it [physical activity] makes me feel better... so that comes out in my class... [if students] get antsy, I can tell they need to move - [but] I don't know if that's the objective truth or if that's me [my interpretation]". Teachers who incorporate physical activity into their own lives may interpret that their students will feel better after an activity break.

\section{Teacher Attributes: Previous Experience}

Many teachers related their current classroom physical activity practices with previous jobs working with children. Previous employment that proved influential to their use of physical activity included: preschool teacher, lifeguard, camp counselor, drama leader, coach, and an adolescent group home leader. Teachers valued physical activity as an effective tool for initiating a change in mood, to instill enjoyment, and for fun. P3 (Gr. 2) explained her work with adolescents, "You know you're spending all day every day with them sometimes. And moving would provide them with a change of scenery, get the blood moving around... Just kind of change perspective sometimes... and so I think that stuck with me." Teachers explained that it was through previous employment opportunities where they gained a repertoire of easy activities. P5 (Gr. 3) illustrated her previous experience as a camp counselor,

I would say because I had more experience in that area [physical activity], it was my go-to right? Like that's what I felt comfortable with... I look back at that experience [of being camp counselor] as being pretty instrumental. I use a lot of those games to get me through those lag moments now [as a teacher]... Like if I felt a lesson wasn't working and I would have had a positive experience with those activities from a camp... where I saw children enjoy themselves, and engage... and being present in the moment.

Teachers chose physical activities from previous experiences that transferred easily into the classroom.

\section{Teacher Attributes: Pedagogical Approach}

Teachers described their pedagogical approach as different from other teachers. They conveyed the strong belief that physical activity was a necessary component to the day and intricately linked with children's learning. P7 (Gr. 2) spoke of her frustration with peers who did not have the same philosophical approach to teaching,

Yeah... I get... angry at some of my... coworkers because they're like, "Yeah, we didn't have time for gym today." And ...I don't know how they [the students] can function to be honest. Because with my kids... sometimes we have "gym" twice. Like sometimes we have afternoon recess... We do movement things in between... And if they missed - if they needed a movement break and they didn't get it... It doesn't matter what you think you're teaching them, they're not getting any of it...

They explained that to meet the needs of their students they were less traditional in their approaches, more tolerant of noise and movement, and more flexible with their timetables than some of their peers.

P2 (Gr. 1-6), P6 (Gr. 5), and P7 (Gr. 2) also believed that students should not be expected to sit for long periods of time, with the theory that children learned better with movement. P2 (Gr. 1-6) illustrated using movement as a teaching tool,

So I'm teaching them rhythm, but I'm getting them to feel it with their bodies...movement helps them internalize their learning. So I try and do things like that... to pull in those kids who don't necessarily get it just from hearing it or seeing it.

P7 (Gr. 2) had also researched physical activity as a strategy for language acquisition, citing two programs, "Lively Letters" (Lively Letters," n.d.) and the "Total Physical Response Technique" (Asher, 1969), which combine movement with words. She stated, "body movement is actually really, really important [for learning]".

\section{Organizational Element: School Culture of Movement}

The third element resonating with teachers was their perception of what the rest of the school staff were doing. At one point in their careers, P4 (Gr. 1/2), P5 (Gr. 3), and P6 (Gr. 5) had belonged to what they described as schools that had a culture of movement, because the school staff embraced a positive mindset towards physical activity. Schools that had a culture of movement had a strong influence on teachers to provide students with physical activity throughout the day. Teachers bought into the practice through administration and collegial support, peer observation, formalized discussions, mentoring, professional development, and the subsequent momentum, excitement, and engagement towards common goals. P5 (Gr. 3) described starting at a new school and her introduction to a whole school activity 
where teachers did not have the option to decline participation.

...the assistant principal said, "Bazinga!" on the intercom. And what that means is that every teacher must drop whatever they're doing and walk outside the classroom and into another random classroom... and we had to dance with the kids. So like that song Happy was playing! And the kids-they know what's happening and they're just waving at you! And you're like, I'm new here! I don't know any other classes! I just ended up in this grade two room, and the grade twos are so happy to dance with you! They don't know me! But they come over and started dancing and they're so excited!! And it gets you to know the other classrooms...I think culture's pretty big. I think role modeling's pretty big...

P6 (Gr. 1/2) began her career at a school that embraced movement and had since worked at two different schools lacking the same whole school approach. She felt schools with a culture of movement had administration that supported teachers to share strategies and model easy games at meetings and professional development days. P5 (Gr. 3) spoke of gaining new physical activity ideas from other teachers, and when asked about the opportunity to observer her peers teaching, she responded, "We do [observe our peers teaching] because we're around each other all the time... We plan together." She further explained that as a new teacher starting at her school, she was immediately expected to share an idea for a classroom physical activity. At a staff meeting, she got up and said,

OK, I think we need a brain break, I think we need to stand up." So [I] we would role model what you can do with your students - you do it with the staff... But it also feels good as an adult right? It was neat how we were allowed to use that time for hands on stuff that we could directly take to our classrooms. And then we did sit down and debrief...

In contrast to the experiences of the teachers working at schools with a culture of movement, P1 (Gr. 5/6), P2 (Gr. 1-6), P3 (Gr. 2), and P7 (Gr. 2) described "teaching in isolation". When asked how their peers provided physical activity, P1 (Gr. 5/6) replied, "I have no idea what the other teachers are doing." P1 explained that teaching is often isolating - there may only be brief opportunities to glance into another teachers' classroom while walking down the hallway. Some teachers felt this was limiting to their use of physical activity, because staff generated excitement when working towards similar goals.

Having a culture of movement makes expectations clear and provides supportive practices. For example, P5 (Gr. 3) explained that in her school, a "Fresh Air Break" was an afternoon outdoor recess occurring whenever it fit with the class schedule. The provision of the break was an expectation within the school, but the teacher was given the flexibility of how and when it would occur. In contrast to the cohesiveness at P5's school, was the isolated dynamic at P7's (Gr. 2) school. Through experimentation, P7 realized that her class worked better in the afternoons after they had an outdoor break. However, despite approval from her principal and confidence in her rationale, she still felt a discomfort that other teachers would question her practice. When there is a common culture towards physical activity, there is an awareness amongst teachers and support towards best practices. P5 stated, "I think culture has a big part to do with it... [when] you see other people taking risks [such as trying new physical activity strategies], you're more likely to take risks like that". Teachers may perceive that having a school culture of movement is conducive to feeling supported in their practice, but is not a limiting factor.

\section{Discussion}

The purpose of this study was to explore elementary teachers' perceptions of their self-initiated implementation of classroom physical activity. Three themes from the findings are important. First, teachers viewed physical activity as a benefit to their students primarily for improved focus on classroom activities. Second, common attributes amongst teachers were: active lifestyle, previous employment experience using physical activity with children, and a pedagogical approach prioritizing physical activity as important to the school day. The third finding was that teachers perceived that it was important for schools to have a culture of movement. These findings contribute to our knowledge of why some teachers may be more likely to perceive a benefit to their teaching time, and choose to initiate and sustain physical activity in their classrooms.

\section{Improved Student Focus}

In this study, when teachers noted that their students were lacking focus, they used physical activity to change the energy level in the classroom. Articulating a connection between improved student focus with physical activity is consistent with other research (Dinkel et al., 2017; Gately et al., 2013; Gibson et al, 2008, Martin \& Murtagh, 2015; Stylianou et al., 2016). Orlick (2012) described focus as an essential skill for learning, distraction control, and mental readiness, but acknowledged that the skill is often expected and not taught. "If children learn to do this effectively [focus], they will gain a distinct advantage in... [all] pursuits..." (Orlick, 1993, p. 91). Teachers who associate increased focus following physical activity may have learned to be more observant of this benefit.

Two teachers linked their previous training on selfregulation with an ability to recognize when students needed to move in order to focus. Self-regulation is defined as an ability to control behavior and focus on the task at hand (Kuypers, 2011). School administration interested in promoting classroom physical activity should consider providing training on self-regulation, as researchers have recorded that some teachers expect that students' behavior will deteriorate if they introduce physical activity in the classroom (Gibson et al., 2008; Howie et al., 2014). In addition, some researchers noted that teachers did not link focus with physical activity (Cothran et al., 2010; Howie et al., 2014; Maeda \& Murata, 2004; McMullen et al., 2014). Hence, there may be valuable ways to promote classroom physical activity to teachers that emphasize the end result of student focus and enhanced uptake of their teaching. 


\section{Teacher Attributes: Active Lifestyle}

Teachers in this study led active lifestyles and valued the benefits of physical activity in their classrooms. They often participated with the students to serve as role models, and to gain the same benefits such as: improved mood, energy, and ability to focus. Teachers valuing physical activity and seeking ways to help benefit their students is a similar finding in other studies (Cothran et al., 2010; Dinkel et al., 2017; Howie et al., 2014; Stylianou et al., 2016). More research could be focused on school wide wellness initiatives that target teachers-helping teachers become more active could increase feelings of wellbeing and an understanding of subsequent increased focus. Additionally, teachers' knowledge or experience with specific activities such as yoga and running and their perceived efficacy in leading those activities in class should also be assessed.

\section{Teacher Attributes: Previous Experience}

Many teachers in this study drew from experiences using physical activity in previous employment positions. Teachers may draw from past experiences due to previous success (Guskey, 2002), and their perceived efficacy levels (Webster, Russ, Vazou, Goh, \& Erwin, 2015). Guskey's (2002) model of The Process of Teacher Change, explained that teachers attribute value to new practices only after they experience successful implementation with their students. Additionally, Webster et al. (2015) stated that teachers' have higher efficacy levels related to physical activity after they have had success in the past. Therefore, pre-service education should prioritize teachers' practice using physical activity integrated with teaching so that teachers gain both experience and efficacy (Webster, Monsma, \& Erwin, 2010).

Teachers reported several values related to their experiences using physical activity: increased student focus, engagement, enjoyment, and changing the energy in the room. Researchers have found that teachers incorporate highly valued beliefs when they are influential on their teaching goals (Kulinna, Silverman, \& Keating, 2000). In other words, teachers may feel confident of their skills in using physical activity, but it is because of their teaching goals that they view the previous outcomes as valuable for the classroom. Brown (2010) stated that the addition of physical activity creates a sense of playfulness, which can be useful in the classroom when a change in a mood or energy level is warranted. Meyer and Turner (2006) suggested that teachers who could consistently provide "positive emotional experiences" (p. 377) contributed to students' engagement and motivation to learn. Teachers who observe the benefits of activity sessions on their students are more apt to value the time spent on those activities.

\section{Teacher Attributes: Pedagogical Approach}

Teachers described their teaching as being less traditional than their peers. Their pedagogical approach, which they defined as the theory of how best to teach, was the view that movement was a necessary strategy for effective teaching and learning. This is supported by other research where teachers using physical activity throughout the day felt they held different philosophical views than their peers who did not implement similar practices (Dinkel et al., 2017).

While many agree that there is a mind-body connection, Wright (2000) argued that schools send the wrong message by separating physical activity from the classroom - as when physical activity is only provided in physical education classes. Teachers in this study reported integrating easy classroom activities such as: push ups, touching three walls, or running outside to the fence and back to the classroom. Cothran et al. (2010) stipulated from their study, that if the goal is to influence teachers to incorporate physical activity daily, then a focus should be made on educating about the body and brain learning link. Education on the body and brain connection could facilitate the necessary attention and increased comprehension towards how the two work together for interrelated benefits in the classroom.

\section{Organizational Element: School Culture of Movement}

Teachers identified that a school with a culture of movement is important for classroom physical activity implementation. School culture is a strong force that permeates expectations and shapes teachers' actions and conversations (Deal \& Peterson, 1999). A school culture brings common goals, accountability, reinforcement, and transparency amongst teachers (Fullan, 2007), and is important when adapting to the distinct needs of the school (Brusseau \& Hannon, 2015). Teachers working in schools with a culture of movement described a sense of priority to implementing activity within their classrooms. They described exposure to peer ideas by planning physical activity strategies together in staff meetings, and the subsequent momentum that ultimately impacts students who receive the benefits of their teachers' day to day learning and collegiality. Hence, they felt supported by administration and peers, and had a strong sense of mentorship, engagement, peer observation, and professional development which are factors identified in other studies as important for teachers incorporating activity breaks (Dinkel, Lee, \& Schaffer, 2016; Dinkel et al., 2017; Naylor, Macdonald, Zebedee, Reed, \& McKay, 2006; Stylianou et al., 2016). Further research could differentiate between the value that teachers attribute to specific components such as peer observation, mentorship, and professional development for incorporating activity breaks.

While all teachers identified that belonging to a school with a culture of movement is ideal, four teachers incorporated classroom physical activity despite teaching in isolation. Dembo and Gibson (1985) described "role performance invisibility" when teachers are unaware of their peers' practices. Ashton and Webb (1986) contended that teachers working in isolation have feelings of uncertainty and self-protection, which can stifle creative processes and taking risks with novel strategies. Therefore, teachers may value the role of the supportive school environment, but it may be teachers' attributes that play a larger role when initiating classroom physical activity. Vazou and Skrade (2014) concluded from their study of 15 teachers implementing an integrated movement program, that teachers' with more years of 
teaching experience were more willing to incorporate non-academic content than newer teachers. Teachers new in their careers are often first concerned with survival and only later target their effects on students (Pataniczek \& Isaacson, 1981). Further research could concentrate on the timing of a teacher employed in a school with a culture of movement. When teachers begin their careers, a school environment with a culture of movement may help expedite the process of incorporating physical activity, providing support, collegiality, and peer observation to the teacher who is developing new classroom strategies.

\section{Implications for Schools}

Our study targeted the perceptions of teachers who prioritized physical activity in their classrooms of their own accord. There may be different ways to influence teachers who do not have the same approaches to their teaching. Our study highlighted teacher approaches that should be further explored: promoting physical activity as a focusing agent for students, promoting teachers' personal activity levels, educating teachers on pedagogical approaches that prioritize physical activity, and establishing resources and support for whole school approaches for instituting a culture of movement. In addition, pre-service training should include physical activity integration so that teachers may begin their careers with experience using physical activity with children and a repertoire of easy activities and games from which to draw. With increasing research being directed at the academic benefits following physical activity sessions, increased efforts should be made to support the integration of best practices in the classroom.

\section{Strengths and Limitations}

Our findings should be contextualized within the strengths and limitations of this study. This was a small study and included interviews with only seven teachers who self-identified using physical activity in the classroom. Therefore, the results are subject to interview bias and social desirability. The teachers themselves were not ethnically diverse, so the findings may not be reflective of teachers who are more diverse in their ethnic backgrounds. Teachers interviewed included all quadrants of a large city, and included one male, which may be appropriate due to the larger number of female teachers employed in the elementary grades. Students, administrators, and parents were not interviewed, nor were teachers who did not use physical activity, which would have offered a broader perspective of physical activity in the classroom. Further research could target the themes highlighted in the results: targeting student focus, teacher knowledge on self-regulation, teacher attributes such as active lifestyles, previous experience with physical activity and children, pedagogical approach, and school culture prioritizing physical activity. Other research areas might include the impact of physical activity occurring outdoors compared to the classroom, and examining the differences between short sessions of high intensity physical activity compared to those only moderately raising the heart rate. These areas may show more efficient use of teaching time and appeal to some teachers.

\section{Conclusion}

In our study we explored elementary teachers' perceptions of their self-initiated use of classroom physical activity for the importance of promoting similar practices. The most compelling finding is that teachers observed students' increased ability to focus on their school-work following physical activity. Teachers unanimously advised that after observing the benefit of focus, they ensured to prioritize physical activity as a necessary component to their teaching. Given the evidence of value for students, more formal support and strategies for teachers should be pursued.

Several strategies to promote classroom physical activity to other teachers should be considered. First, physical activity should be integral to teaching during the preservice years. Teachers should graduate with a repertoire of easy to use physical activities to renew student energy and focus when behavioral cues such as sleepy or restless students are observed. Physical activity should be infused into the classroom throughout the day, not separated and provided only in physical education classes. If taught in this way, teachers would not have to think about adding in physical activity sessions, it would become intuitive. Second, schools should be encouraged, and provided the resources to create a culture of movement. Administrative support, formal discussions, peer mentorship, and sharing of physical activity strategies are deemed helpful by teachers to confidently implement physical activity in their classrooms. Finally, teachers can be taught about physical activity as a strategy for selfregulation, and learn the behavioral cues indicative of students lacking focus on their work. Training does not have to be complicated. Teachers in this study demonstrated that it is simple and easy physical activity used throughout the day that provided value and improved the classroom learning environment.

\section{References}

Asher, J.J. (1969). The total physical response approach to second language learning. The Modern Language Journal, 53(1), 3-17. doi:10.2307/322091

Ashton, P.T., \& Webb, R.B. (1986). Making a difference: Teachers' sense of efficacy and student achievement. White Plains, NY: Longman.

Bartholomew, J.B., \& Jowers, E.M. (2011). Physically active academic lessons in elementary children. Preventive Medicine, 52, S51-S54. doi:10.1016/j.ypmed.2011.01.017

Brown, S. (2010). Play: How it shapes the brain, opens the imagination, and invigorates the soul. New York: Penguin Group.

Brusseau, T.A., \& Hannon, J.C. (2015). Impacting children's health and academic performance through comprehensive school physical activity programming. International Electronic Journal of Elementary Education, 7(3), 441-450.

Carlson, S.A., Fulton, J.E., Lee, S.M., Maynard, L.M., Brown, D.R., Kohl, H.W., \& Dietz, W.H. (2008). Physical education and academic achievement in elementary school: Data from the early childhood longitudinal study. American 
Journal of Public Health, 98(4),721-727. doi: 10.2105/AJPH.2007.117176

Centers for Disease Control and Prevention (2007). School health policies and programs study. Atlanta, GA: Retrieved from http://files.eric.ed.gov/fulltext/ED498697.pdf

Charmaz, K. (2014). Constructing grounded theory: A practical guide through qualitative analysis (2nd ed.). Thousand Oaks, CA: Sage.

Cothran, D.J., Hodges-Kulinna, P.H., \& Garn, A.C. (2010). Clasroom teachers and physical activity integration. Teaching and Teacher Education, 26, 1381-1388. doi:10.1016/j.tate.2010.04.003

Cotman, C.W., \& Berchtold, N.C. (2002). Exercise: A behavioral intervention to enhance brain health and plasticity. TRENDS in Neurosciences, 25(6), 295-301. doi:10.1016/SO166-2236(02)02143-4

Deal, T.E., \& Peterson, K.D. (1999). Shaping school culture: The heart of leadership. San Francisco, CA: Jossey-Bass.

Dembo, M.H., \& Gibson, S. (1985). Teachers' sense of efficacy: An important factor in school improvement. The Elementary School Journal, 86(2), 173-184. doi:10.1086/461441

Dinkel, D.M., Lee, J.M., \& Schaffer, C. (2016). Examining the knowledge and capacity of elementary teachers to implement classroom physical activity breaks. International Electronic Journal of Elementary Education, 9(1), 182-196.

Dinkel, D.M., Schaffer, C., Snyder, K., \& Lee J.M. (2017). They just need to move: teachers' perception of classroom physical activity breaks. Teaching and Teacher Education, 63, 186-195. doi:10.1016/j.tate.2016.12.020

Donnelly, J.E, \& Lambourne, K. (2011). Classroom-based physical activity, cognition, and academic achievement. Preventive Medicine, 52, S36-S42. doi:10.1016/j.ypmed.2011.01.021

Erwin, H., Fedewa, A., \& Ahn, S. (2013). Student academic performance outcomes of a classroom physical activity intervention: A pilot study. International Electronic Journal of Elementary Education 5(2), 109-124.

Fullan, M. (2007). The new meaning of educational change (4th ed.). New York/London: Teachers College Press.

Gately, P., Curtis, C., \& Hardaker, R. (2013). An evaluation in UK schools of a classroom-based physical activity programme -TAKE 10!®: A qualitative analysis of the teachers' perspective. Education and Health, 31(4), 72-78.

Gibson, C.A., Smith, B.K., DuBose, K.D., Greene, J.L., Bailey, B.W., Williams, S.L.,...Donnelly, J.E. (2008). Physical activity across the curriculum: Year one process evaluation results. International Journal of Behavioral Nutrition and Physical Activity, 5(36) 1-7. doi:10.1186/1479-5868-5-36

Guskey, T.R. (2002). Professional development and teacher change. Teachers and Teaching, 8, 381-391. doi:10.1080/135406002100000512

Hallal, P.C., Andersen, L.B., Bull, F.D., Guthold, R., Haskell, W., \& Ekelund, U. (2012). Global physical activity levels: surveillance progress, pitfalls, and prospects. The Lancet, 280, 247-257. doi:10.1016/S0140-6736(12)-60633-3

Hill, L., Williams, J.H., Aucott, L., Milne, J., Thomson, J., Greig, J.,...Mon-Williams, M. (2010). Exercising attention within the classroom. Developmental Medicine and Child Neurology, 52(10), 929-934. doi:10.1111/j.14698749.2010.03661.x

Hill, L., Williams, J.H., Aucott, L., Thomson, J., MonWilliams, M. (2011). How does exercise benefit performance on cognitive tests in primary-school pupils? Developmental Medicine and Child Neurology, 53(7), 630635. doi:10.1111/j.1469-8749.2011.03954.x

Hillman, C.H., Erickson, K.I., \& Kramer, A.F. (2008). Be smart, exercise your heart: Exercise effects on brain and cognition. Nature Publishing Group, 9, 58-65. doi:10.1038/nrn2298

Howie, E.K., Newman-Norlund, R.D., \& Pate, R.R. (2014). Smiles count but minutes matter: Responses to classroom exercise breaks. American Journal of Health Behavior, 38(5), 681-689. doi:10.5993/AJHB.38.5.5

Khan, N.A., \& Hillman, C.H. (2014). The relation of childhood physical activity and aerobic fitness to brain function and cognition: A review. Pediatric Exercise Science, 26, 138-146. doi:org/10.1123/pes.2013-0125

Kibbe, D.L., Hackett, J., Hurley, M., McFarland, A., Schubert, K.G., Schultz, A., \& Harris, S. (2011). Ten Years of Take 10 !®: Integrating physical activity with academic concepts in elementary school classrooms. Preventive Medicine, 52, S43. doi:10.1016/j.ypmed.2011.01.025

Kulinna, P.H., Silverman, S., \& Keating, X.D. (2000). Relationship between teachers' belief systems and actions toward teaching physical activity and fitness. Journal of Teaching in Physical Education, 19, 206-221.

Kuypers, L.M. (2011). The zones of regulation: A curriculum designed to foster self-regulation and emotional control. San Jose, CA: Think Social.

Lee, I.M., Shiroma, E.J., Lobelo, F., Puska, P., Blair, S.N., \& Katzmarzyk, P.T. (2012). Effect of physical inactivity on major non-communicable diseases worldwide: an analysis of burden of disease and life expectancy. Lancet, 380(9838), 219-220. doi:10.1016/S0140-6736(12)61031-9

Lively Letters (n.d.). Reading with TLC. Retrieved May 14, 2017, http://www.readingwithtlc.com/lively-letters.html

Maeda, J.K., \& Murata, N.M. (2004). Collaborating with classroom teachers to increase daily physical activity: The GEAR program. Journal of Physical Education, Recreation and Dance, 42-46. doi:10.1080/07303084.2004.10607239

Maeda, J.K., \& Randall, L.M. (2003). Can academic success come from five minutes of physical activity? Brock Education, 13(1), 14-22. Retrieved from http://www.sciencedirect.com.ezproxy.ib.ucalgary.ca/scie nce/article/pii/S0091743511000557

Mahar, M.T., Murphy, S.K., RowE, D.A., Golden, J., Shields, A.T., \& Raedeke, T.D. (2006). Effects of a classroom-based program on physical activity and on-task behavior. 
American College of Sports Medicine, 2086-2094. doi:10.1249/01.mss.0000235359

Martin, R., \& Murtagh, E.M. (2015). Preliminary findings of active classrooms: An intervention to increase physical activity levels of primary school children during class time. Teaching and Teacher Education, 52, 113-127. doi:10.1016/j.tate.2015.09.007

McMullen, J., Kulinna, P., \& Cothran, D. (2014). Physical activity opportunities during the school day: Classroom teachers' perception of using activity breaks in the classroom. Journal of Teaching in Physical Education, 33, 511-527. doi:10.1123/jtpe.2014-0062

Meyer, D.K, \& Turner, J.C. (2006). Re-conceptualizing emotion and motivation to learn in classroom contexts. Educational Psychology Review, 18, 377-390. doi:10.1007/s10648-006-9032-1

Miramontez, S.K.H., \& Schwartz, I.S. (2016). The effects of physical activity on the on-task behavior of young children with autism spectrum disorders. International Electronic Journal of Elementary Education, 9(2), 405-418.

Naylor, P.J., Macdonald, H.M., Zebedee, J.A., Reed, K.E., \& McKay, H.A. (2006). Lessons learned from Action Schools! BC-An 'active school' model to promote physical activity in elementary schools. Journal of Science and Medicine in Sport, 9, 413-423. doi:10.1016/j.jsams.2006.06.013

Orlick, T. (1993). Free to feel great: Teaching children to excel at living. Carp, ON: Creative Bound.

Orlick, T. (2012). Dr. Terry Orlick. In M.W. Aoyagi \& A. Poczwardowski (Eds.), Expert approaches to sport psychology: Applied theories of performance excellence. (167184). Morgantown, WV: West Virginia University.

ParticipACTION (2016). Are Canadian kids too tired to move? The 2016 ParticipACTION report card on physical activity for children and youth. Toronto: ParticipACTION.

Pataniczek, D., \& Isaacson, N.S. (1981). The relationship of socialization and the concerns of beginning secondary teachers. Journal of Education, 32(3), 14-17. doi: $10.1177 / 002248718103200303$

Reed, J.A., Einstein, G., Hahn, e., Hooker, S.P., Gross, V.P., \& Kravitz, J. (2010). Examining the impact of integrating physical activity on fluid intelligence and academic performance in an elementary school setting: A preliminary investigation. Journal of Physical Activity \& Health, 7(3), 343-351. Retrieved from http://www-ncbinlm-nih-gov.ezproxy.lib.ucalgary.ca/pubmed/20551490

Roberts, K.C., Shields, M., de Groh, M., Aziz, A., \& Gilbert, J. (2012). Overweight and obesity in children and adolescents: Results from the 2009 to 2011 Canadian health measures survey. Statistics Canada Health Reports. Catalogue no. 82-003-x

Sibley, B.A., \& Etnier, J.L. (2003). The relationship between physical activity and cognition in children: A metaanalysis. Pediatric Exercise Science, 15, 243-256. doi:10.1123/pes.15.3.243

Singh, A.S., Mulder, C., \& Twisk, J.W.R. (2008). Tracking of childhood overweight into adulthood: A systematic review of the literature. Obesity Reviews 9, 474-488. doi:10.1111/j.1467-789X.2008.00475.x

Statistics Canada (2011). National Household Survey: Data Tables. Retrieved from http://www12.statcan.gc.ca/nhsenm/2011/dp-pd/dt-td/Rp-

eng.cfm?TABID $=2 \& L A N G=E \& A P A T H=3 \& D E T A I L=0 \& D I M=0$ $\& F L=A \& F R E E=0 \& G C=0 \& G I D=1118423 \& G K=0 \& G R P=0 \& P I D$ $=105395 \& P R I D=0 \& P T Y P E=105277 \& S=0 \& S H O W A L L=0 \& S U$ $\mathrm{B}=0 \&$ Temporal $=2013 \& \mathrm{THEME}=95 \& \mathrm{VID}=0 \& \mathrm{VNAMEE}=\& \mathrm{VN}$ $\mathrm{AMEF}=\& \mathrm{D} 1=0 \& \mathrm{D} 2=0 \& \mathrm{D} 3=0 \& \mathrm{D} 4=0 \& \mathrm{D} 5=0 \& \mathrm{D} 6=0$

Stylianou, M., Kulinna, P.H., \& Naiman, T. (2016). '...because there's nobody who can just sit that long': Teacher perceptions of classroom-based physical activity and related management issues. European Physical $\begin{array}{llll}\text { Education } & \text { Review, 22(3), 390-408. }\end{array}$ doi:10.1177/1356336X15613968

Vazou, S., \& Skrade, M. (2014). Teachers' reflections from integrating physical activity in the academic classroom. Research Quarterly for Exercise and Sport, 85, A38. doi:10.1016/j.ecresq.2012.05.003

World Health Organization (2016). Physical activity: Fact sheet. Retrieved from: http://www.who.int/mediacentre/factsheets/fs385/en/

Webster, C., Monsma, E., \& Erwin, H. (2010). The role of biographical characteristics in preservice classroom teachers' school physical activity promotion attitudes. Journal of Teaching in Physical Education, 29(4), 358-377. doi:10.1123/jtpe.29.4.358

Webster, C., Russ, L., Vazou, T., Goh, R.L., \& Erwin, H. (2015). Integrating movement in academic classrooms: understanding, applying and advancing the knowledge base. Obesity Reviews, 16, 691-701. doi:10.1111/obr.12285

Wright, J. (2000). Bodies, meanings and movement: A comparison of the language of a physical education lesson and a Feldenkrais movement class. Sport,

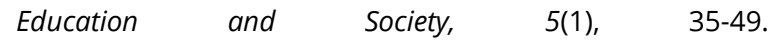
doi:10.1080/135733200114424 

This page is intentionally left blank

www.iejee.com 